STRUCTURAL BIOLOGY

ISSN 2059-7983

Received 11 June 2021

Keywords: FAD-dependent oxidoreductases; GMC oxidoreductases; Chaetomium thermophilum; crystallographic fragment screening; corrigendum; synchrotron facilities.
Accepted 11 June 2021

\section{Crystallographic fragment screening-based study of a novel FAD-dependent oxidoreductase from Chaetomium thermophilum. Corrigendum}

\author{
Leona Švecová, ${ }^{\mathrm{a}, \mathrm{b} *}$ Lars Henrik Østergaard, ${ }^{\mathrm{c}}$ Tereza Skálová, ${ }^{\mathrm{a}}$ Kirk Matthew \\ Schnorr, ${ }^{\mathrm{c}}$ Tomáš Koval', ${ }^{\mathrm{a}}$ Petr Kolenko, ${ }^{\mathrm{a}, \mathrm{b}}$ Jan Stránský, ${ }^{\mathrm{a}}$ David Sedlák, Jarmila \\ Dušková, ${ }^{\mathrm{a}}$ Mária Trundová, ${ }^{\mathrm{a}}$ Jindřich Hašek ${ }^{\mathrm{a}}$ and Jan Dohnálek ${ }^{\mathrm{a} *}$
}

\begin{abstract}
anstitute of Biotechnology of the Czech Academy of Sciences, v.v.i., Průmyslová 595, 25250 Vestec, Czech Republic, ${ }^{b}$ Faculty of Nuclear Sciences and Physical Engineering, Czech Technical University in Prague, Břehová 7 , 11519 Prague 1, Czech Republic, 'Novozymes A/S, Biologiens Vej 2, 2800 Kgs. Lyngby, Denmark, and ${ }^{\mathbf{d}}$ CZ-OPENSCREEN: National Infrastructure for Chemical Biology, Institute of Molecular Genetics of the Czech Academy of Sciences, v.v.i., Vídeňská 1083, 14220 Prague, Czech Republic. *Correspondence e-mail: leona.svecova@ibt.cas.cz, dohnalek@ibt.cas.cz
\end{abstract}

The synchrotron facilities used in collecting the data for the article by Švecová et al. [(2021), Acta Cryst. D77, 755-775] are acknowledged.

In the article by Švecová et al. (2021) proper acknowledgement was not made to the two synchrotron sources used to collect the data. Here we update the acknowledgements section and add two references.

In Section 2.6 of the article the third sentence should include citations as follows: Diffraction data were collected either on beamline P13 of the PETRA III synchrotronradiation source, DESY, Hamburg, Germany (Cianci et al., 2017) or on beamlines 14.1 and 14.2 of the BESSY II synchrotron-radiation source, Helmholz-Zentrum, Berlin, Germany (Mueller et al., 2015).

In Section 2.8 of the article the third sentence should include a citation as follows: For data collection, an HR2000+ES UV-Vis spectrophotometer (OceanOptics) at the MX-SpectroLab at BESSY II, Helmholz Zentrum, Berlin, Germany (Mueller et al., 2015) was used.

An updated ackowledgements section is given below.

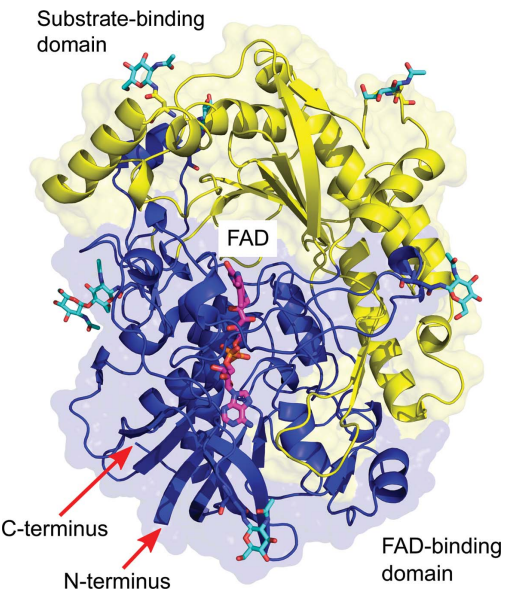

\section{Acknowledgements}

We would like to thank Drs Jiří Pavlíček, Petr Pompach, Pavla Vaňková and Tatsiana Charnavets from the Centre of Molecular Structure at Biocev, Dr Petr Bartůněk from CZOPENSCREEN, and Dr Sofia Ferreira from Refeyn Ltd for assistance with data acquisition. We would like to acknowledge all staff of BL14.1 and 14.2 at the BESSY II electron storage ring operated by the Helmholtz-Zentrum Berlin for help and support with diffraction data collection in years 2015-2020 and Dr Thomas Hauss for assistance with spectroscopy measurements. We also acknowledge support and assistance in data collection at beamline P13 operated by EMBL Hamburg at the PETRA III storage ring (DESY, Hamburg, Germany), especially Dr Isabel Bento. 


\section{References}

Cianci, M., Bourenkov, G., Pompidor, G., Karpics, I., Kallio, J., Bento, I., Roessle, M., Cipriani, F., Fiedler, S. \& Schneider, T. R. (2017). J. Synchrotron Rad. 24, 323-332.

Mueller, U., Förster, R., Hellmig, M., Huschmann, F. U., Kastner, A., Malecki, P., Pühringer, S., Röwer, M., Sparta, K., Steffien, M.,
Ühlein, M., Wilk, P. \& Weiss, M. S. (2015). Eur. Phys. J. Plus, 130, 141-150.

Švecová, L., Østergaard, L. H., Skálová, T., Schnorr, K. M., Koval’, T., Kolenko, P., Stránský, J., Sedlák, D., Dušková, J., Trundová, M., Hašek, J. \& Dohnálek, J. (2021). Acta Cryst. D77, 755775 . 